\title{
Magnetic resonance spectroscopic determination of a neuronal and axonal marker in white matter predicts reversibility of deficits in secondary normal pressure hydrocephalus
}

\author{
A Shiino, Y Nishida, H Yasuda, M Suzuki, M Matsuda, T Inubushi
}

J Neurol Neurosurg Psychiatry 2004;75:1 141-1 148. doi: 10.1136/jnnp.2003.019943

See end of article for authors' affiliations

Correspondence to:

Dr A Shiino, Department of

Neurosurgery, Shiga

University of Medical

Science, Seta, Ohtsu,

Shiga 520-2192, Japan;

shiino@belle.shiga-med.

ac.jp

Received 30 May 2003

Revised

26 September 2003

Accepted 26 October 2003

\begin{abstract}
Background: Normal pressure hydrocephalus (NPH) is considered to be a treatable form of dementia, because cerebrospinal fluid (CSF) shunting can lessen symptoms. However, neuroimaging has failed to predict when shunting will be effective.

Objective: To investigate whether ${ }^{1} \mathrm{H}$ (proton) magnetic resonance (MR) spectroscopy could predict functional outcome in patients after shunting.

Methods: Neurological state including Hasegawa's dementia scale, gait, continence, and the modified Rankin scale were evaluated in 21 patients with secondary NPH who underwent ventriculo-peritoneal shunting. Outcomes were measured postoperatively at one and 12 months and were classified as excellent, fair, or poor. MR spectra were obtained from left hemispheric white matter.

Results: Significant preoperative differences in N-acetyl aspartate (NAA)/creatine $(\mathrm{Cr})$ and NAA/choline (Cho) were noted between patients with excellent and poor outcome at one month $(p=0.0014$ and 0.0036 , respectively). Multiple regression analysis linked higher preoperative $\mathrm{NAA} / \mathrm{Cr}$ ratio, gait score, and modified Rankin scale to better one month outcome. Predictive value, sensitivity, and specificity for excellent outcome following shunting were $95.2 \%, 100 \%$, and $87.5 \%$. Multiple regression analysis indicated that NAA/Cho had the best predictive value for one year outcome $(p=0.0032)$; predictive value, sensitivity, and specificity were $89.5 \%, 90.0 \%$, and $88.9 \%$.

Conclusions: MR spectroscopy predicted long term post-shunting outcomes in patients with secondary $\mathrm{NPH}$, and it would be a useful assessment tool before lumbar drainage.
\end{abstract}

$\mathrm{N}$ ormal pressure hydrocephalus (NPH) is a chronic communicating hydrocephalus that presents with the triad of gait disturbance, cognitive impairment, and urinary incontinence. Patients' functional status can improve dramatically after ventricular shunt placement, even when the cerebrospinal fluid (CSF) pressure is within the normal range. ${ }^{1}$ This pathophysiologically intriguing condition is often difficult to differentiate from irreversible brain degeneration. Among patients diagnosed with idiopathic NPH, shunting is clinically effective in only $30 \%,{ }^{2}$ while in patients with secondary NPH, at least $20-30 \%$ of shunts provide little benefit. ${ }^{2}{ }^{3}$ Despite many clinical studies conducted over the past three decades, difficulties persist in identifying patients with true functional reversibility of NPH on the basis of clinical and radiographic criteria. ${ }^{2}$

$\mathrm{N}$-acetyl aspartate (NAA) is a metabolite localised almost exclusively in neurones and their processes ${ }^{4}$ and is accepted widely as a neuronal marker. Neurones in the central nervous system have an extremely limited capacity for regeneration, and a decrease in NAA has been interpreted as indicating neuronal loss. For example, NAA reduction has been observed in patients with vascular dementia such as subcortical arteriosclerotic encephalopathy. ${ }^{56}$ On the other hand, in NPH, even when cerebral function is impaired by ventricular enlargement, any neuronal loss should be minimal; thus the amounts of NAA in the brain should remain within the normal range. Magnetic resonance (MR) spectroscopy can be carried out preoperatively to measure this neuronal marker and thus assess reversibility of cerebral dysfunction. In this study we investigated whether preoperative MR spectroscopy could predict outcome in NPH patients who underwent CSF shunting.

\section{METHODS}

Criteria for identifying probable NPH were clinical signs of gait disturbance and either cognitive impairment or urinary incontinence, ventricular enlargement on computed tomography (CT) or MR imaging, and a CSF pressure of less than $20 \mathrm{~mm} \mathrm{Hg}$. Between November 1992 and October 2001 shunting was carried out at our institution in 49 patients diagnosed with probable NPH. Before shunting, we selected 23 of these patients with no brain lesion such as infarction or haemorrhage evident on MR imaging or CT. Periventricular white matter changes such as periventricular hyperintensity $(\mathrm{PVH})$ or deep white matter hyperintensity (DWMH) were not considered grounds for exclusion. Two additional patients were excluded ultimately because of technical problems. Consequently data from 21 patients were analysed. Subjects included eight men and 13 women whose ages ranged from 38 to 77 years (mean (SD), 62 (10) years). Underlying causes of communicating hydrocephalus

Abbreviations: AIC, Akaike's information criterion; AID, automatic interaction detection; $\mathrm{CBF}$, cerebral blood flow; Cho, choline compounds; $\mathrm{Cr}$, creatine; DWMH, deep white matter hyperintensity; $\mathrm{Gln} / \mathrm{Glu}$, glutamine and glutamate; HDS-R, Hasegawa's revised dementia scale; mlns, myoinositol; NAA, N-acetyl aspartate; NPH, normal pressure hydrocephalus; OEF, oxygen extraction fraction; PRESS, point resolved, spatially localised spectroscopy; PVH, periventricular hyperintensity; VOI, volume of interest 


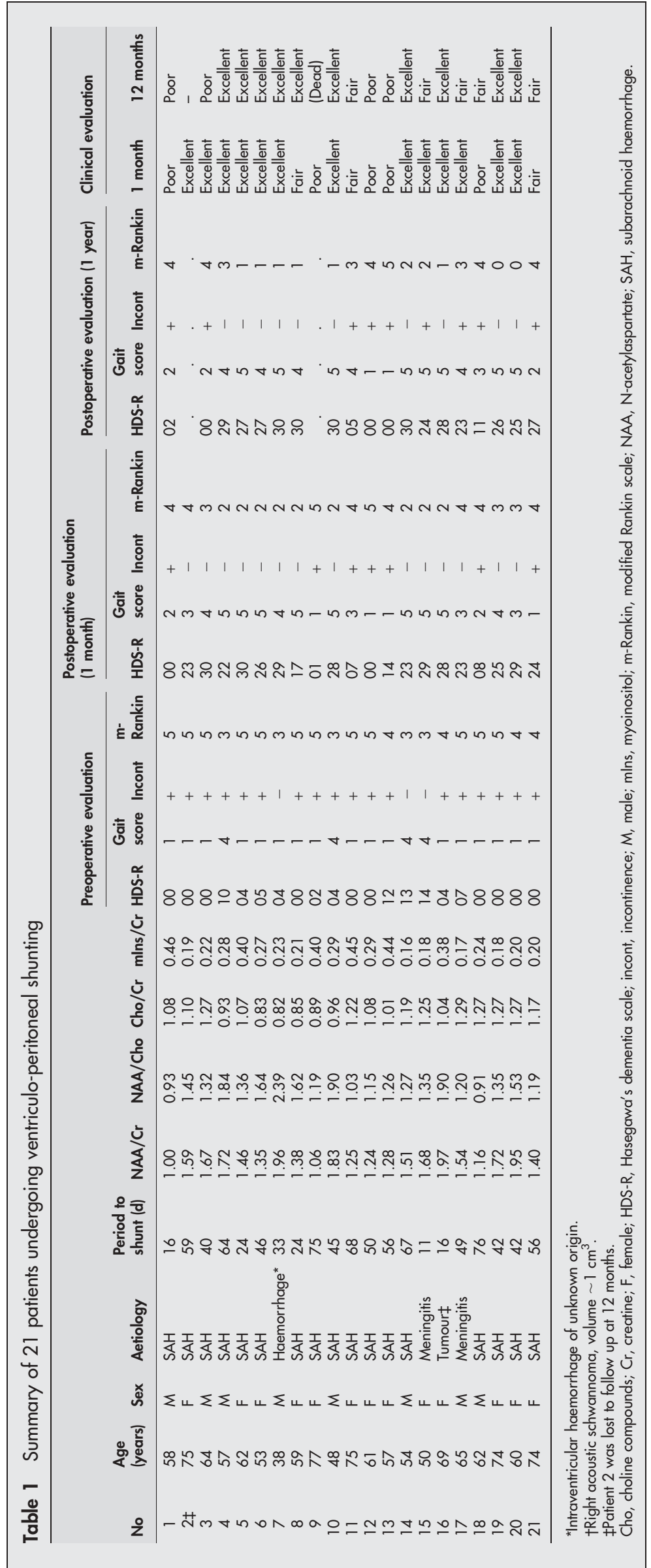



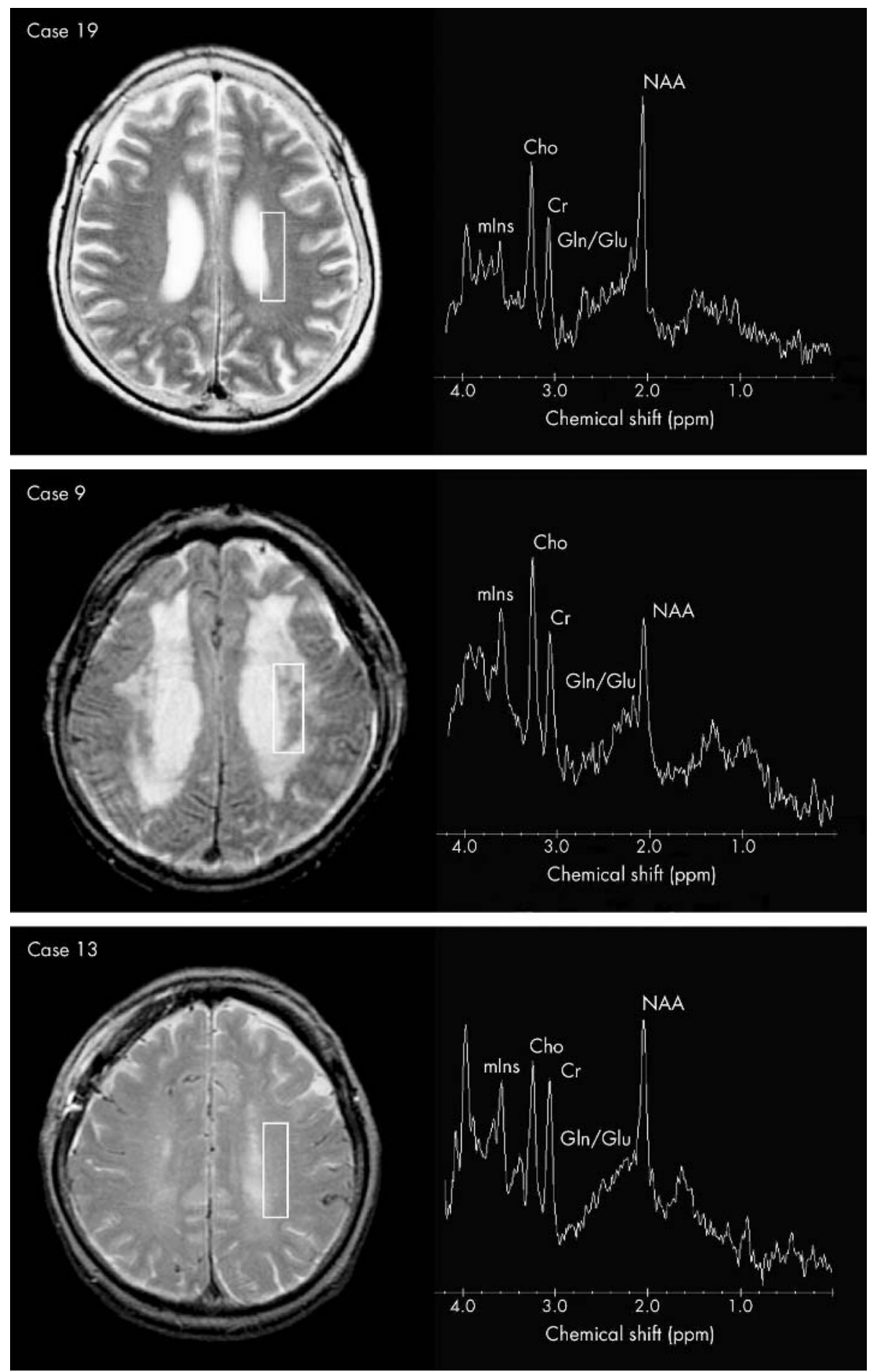

Figure 1 Representative preoperative T2 weighted magnetic resonance (MR) images and MR spectra. The white rectangles indicate the region of interest for MR spectroscopy. Top panel: a patient whose outcome was excellent (case 19). Middle panel: a patient whose outcome was poor (case 9). Bottom panel: a patient whose outcome was poor (case 13). Cho, choline compounds; Cr, creatine; Gln/Glu, glutamine and glutamate; mlns, myoinositol; NAA, N-acetylaspartate.

included ruptured cerebral aneurysm in 14 patients, subarachnoid haemorrhage of unknown origin in three, brain tumour in one, meningitis in two, and intraventricular haemorrhage in one. Patients with idiopathic NPH were not included.

Before ventriculo-peritoneal shunting, all patients underwent a trial of lumbar drainage, and improvement in their neurological condition was confirmed. Slight neurological changes such as improvement in the patient's response time and increased duration of spontaneous eye opening were also considered to represent improvement. A low pressure valve was used for the ventriculo-peritoneal shunt, and function of the shunt system was monitored closely.

\section{MR imaging and spectroscopy}

MR imaging and MR spectroscopy were carried out with a $1.5 \mathrm{~T}$ whole body magnetic resonance device (General Electric, Milwaukee, Wisconsin, USA), using a conventional 


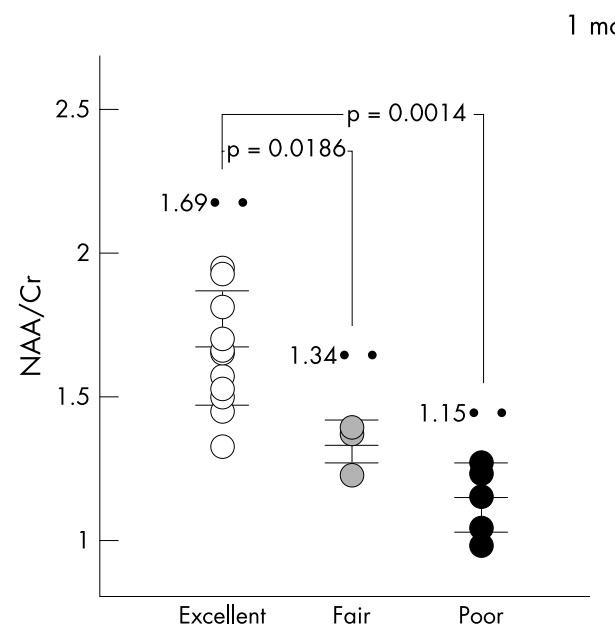

1 month
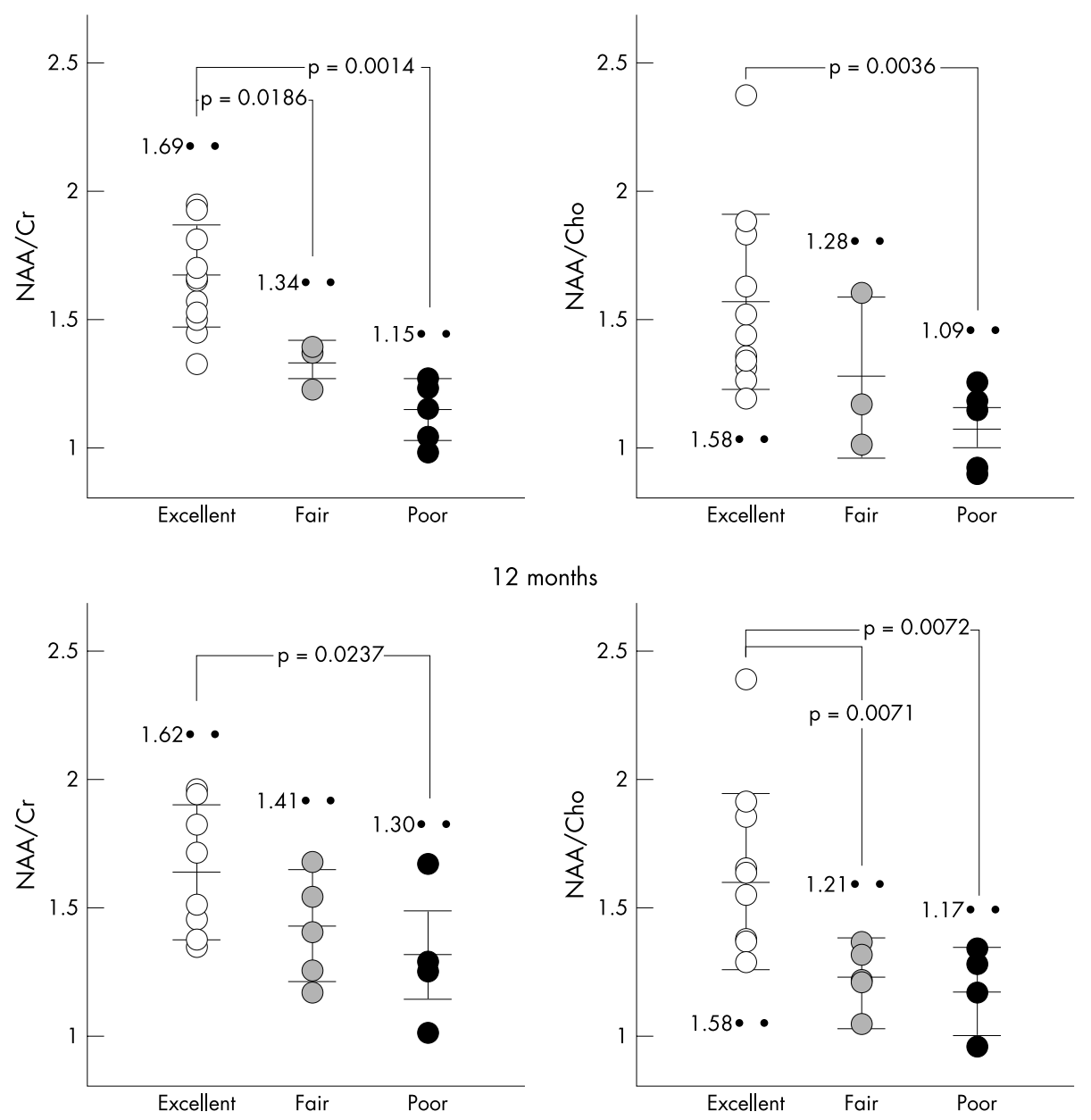

2 months

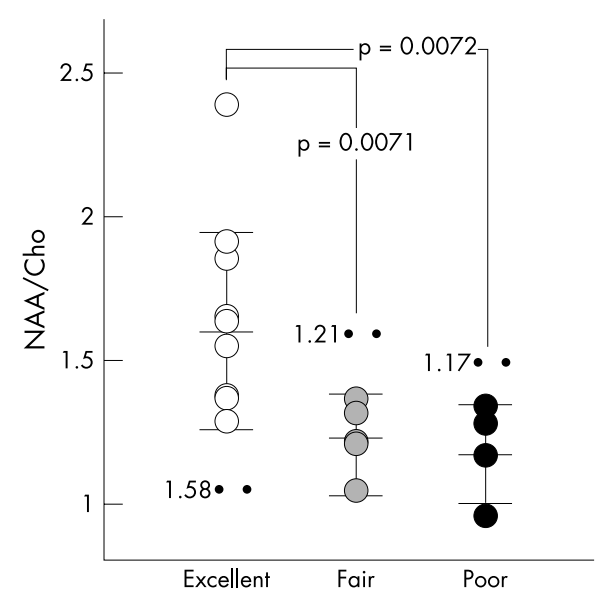

Figure 2 Mean and standard deviation (SD) of NAA/Cr and NAA/Cho ratios at one and 12 months after ventriculo-peritoneal shunting. Statistical analysis was done using the Mann-Whitney U test. NAA, N-acetyl aspartate; $\mathrm{Cr}$, creatine; Cho, choline compounds.

birdcage head coil, within three days before and again one month after ventriculo-peritoneal shunting. The long axis of the body of the lateral ventricle was aligned orthogonally to the " $\mathrm{Z}$ " axis of the magnet by positioning the subject's neck. The imaging protocol included Tl weighted spin echo images $(\mathrm{TR} / \mathrm{TE}=500 / 30 \mathrm{~ms})$ as well as T2 weighted images (TR/ $\mathrm{TE}=2400 / 100 \mathrm{~ms}$ ). A volume of interest (VOI) of $15 \mathrm{~mm}$ thickness was located in the white matter lateral to the body of the lateral ventricle. The width and the length of the VOI, adjusted to avoid grey matter, were approximately $1.5 \mathrm{~cm}$ and $2.5 \mathrm{~cm}$, respectively (fig 1). Proton MR spectroscopy was carried out using a point resolved, spatially localised spectroscopy (PRESS) sequence with the following parameters: time of echo (TE), $25 \mathrm{~ms}$; time of repetition (TR), $2000 \mathrm{~ms}$; number of acquisitions, 128. Shimming was done several times over the selected volume until the line width of the proton signal was reduced to within $4 \mathrm{~Hz}$, and water suppression pulses were adjusted until 95\% water suppression could be achieved.

Data were extracted randomly and processed by a single investigator (YN) who was blinded to patients' clinical status, using a Sun Sparc station 5 workstation (Sun Microsystems, Mountain View, California, USA). Metabolite peaks were identified by their chemical shift and coupling pattern as described in a previous report. ${ }^{7}$ Each metabolite was expressed as a ratio to the creatine peak. Unfortunately, technical difficulties in measurement of peak area precluded analysis of the glutamate/glutamine peaks. We did not use a water signal as an internal standard because the selected area for VOI sometimes included intraventricular CSF.

\section{Clinical assessment}

Clinical effectiveness of shunting was assessed by scoring of dementia, gait disturbance, and urinary incontinence. The severity of dementia was determined using Hasegawa's revised dementia scale (HDS-R). ${ }^{8}$ The severity of gait disturbance was graded from 1 to 5 as follows: 1, inability to walk; 2, ability to walk with assistance; 3, ability to walk independently with a cane; 4 , ability to walk fully unassisted; 5 , absence of gait disturbance. Presence or absence of urinary incontinence was assessed from the nursing records. The modified Rankin scale ${ }^{9}$ was used for assessment of activity of daily living. These assessments were all made on the day before shunting and again at one month and 12 months after ventriculo-peritoneal shunt placement. Ventriculo-peritoneal shunting was carried out when patients had recovered clinically from the primary disease, and fluctuation of HDS-R scores remained within 5 points.

For generalised evaluation of the clinical outcome, patients were divided into three groups according to their scores at one month and 12 months after shunting. Outcome in patients who recovered from dementia (HDS-R $\geqslant 20$ ), became able to walk independently (gait score $\geqslant 3$ ), and regained urinary continence was classified as excellent. Outcome in patients who were demented (HDS-R $<20$ ), were unable to walk independently (gait score $\leqslant 2$ ), and were incontinent 


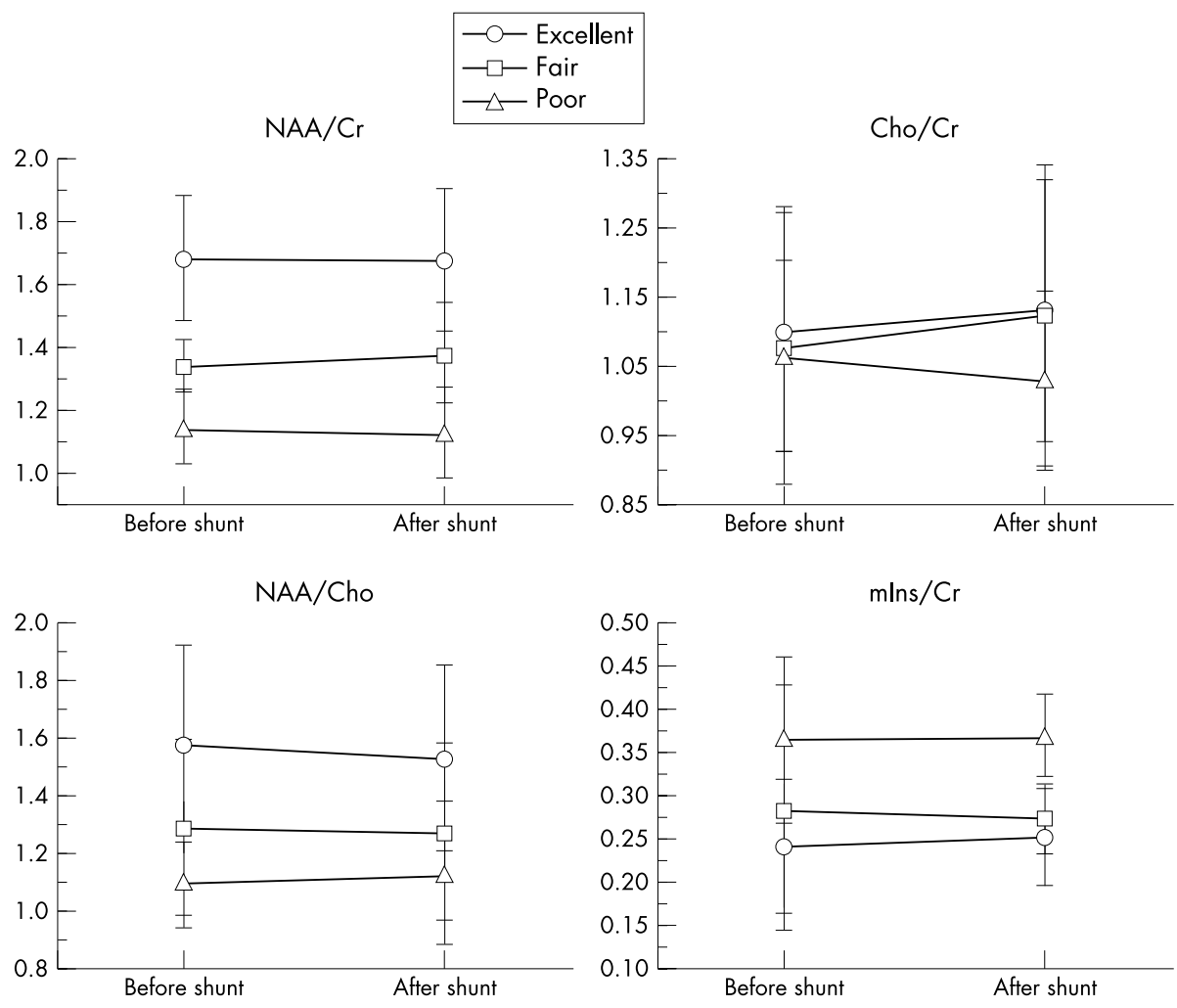

Figure 3 Mean $\mathrm{NAA} / \mathrm{Cr}, \mathrm{NAA} / \mathrm{Cho}, \mathrm{Cho} / \mathrm{Cr}$, and $\mathrm{mlns} / \mathrm{Cr}$ ratios before and one month after ventriculo-peritoneal shunting. Error bars = SD. No significant changes were observed (Student's paired $t$ test) in magnetic resonance spectra after ventriculo-peritoneal shunting. Cho, choline compounds; $\mathrm{Cr}$, creatine; mlns, myoinositol; NAA, N-acetylaspartate.

was classified as poor. In the remaining patients, who showed incomplete recovery from these three symptoms, the outcome was classified as fair.

\section{Statistical analyses}

The Statistical Analysis System (SAS Institute, Cary, North Carolina, USA) was used. Spearman's rank correlation coefficients were used to investigate the relation between neurological scores and MR spectra obtained preoperatively. The significance of differences in $\mathrm{NAA} / \mathrm{Cr}$ and $\mathrm{NAA} / \mathrm{Cho}$ between the three groups defined by their clinical outcome was evaluated by the Mann-Whitney test. The KruskalWallis test was used to evaluate differences in preoperative variables between the three groups. For this analysis, urinary incontinence and sex were each expressed as a binary value (incontinence, 1; no incontinence, 2; male, 1; female, 2). Multiple regression analysis was used to determine the preoperative variables most importantly related to outcome; outcomes were expressed as excellent, 1; fair, 2; or poor, 3. To select the best combination of preoperative variables, Akaike's information criterion (AIC) method was used. The automatic interaction detection (AID) method was adopted to determine the important preoperative variables related to outcome.

\section{RESULTS}

Data for the 21 patients are summarised in table 1 . One month after ventriculo-peritoneal shunting, the numbers of patients who showed no change in HDS-R, gait, or modified

Table 2 Differences in preoperative variables in each outcome group

\begin{tabular}{|c|c|c|c|c|c|c|c|c|}
\hline \multirow[b]{2}{*}{$\begin{array}{l}\text { Preoperative } \\
\text { variables }\end{array}$} & \multicolumn{4}{|l|}{1 month } & \multicolumn{4}{|l|}{12 months } \\
\hline & $\begin{array}{l}\text { Excellent } \\
(n=13)\end{array}$ & Fair $(n=3)$ & Poor $(n=5)$ & $\begin{array}{l}\text { p Value } \\
\text { (Kruskal- } \\
\text { Wallis) }\end{array}$ & $\begin{array}{l}\text { Excellent } \\
(n=10)\end{array}$ & Fair $(n=5)$ & Poor $(n=4)$ & $\begin{array}{l}\text { p Value } \\
\text { (Kruskal- } \\
\text { Wallis) }\end{array}$ \\
\hline Age (years) & $63(8)$ & $69(9)$ & $60(10)$ & $0.3458^{*}$ & $57(10)$ & $65(10)$ & $60(3)$ & $0.2609^{*}$ \\
\hline Male/female & $6 / 7$ & $0 / 3$ & $2 / 3$ & $0.4739^{*}$ & $6 / 7$ & $0 / 3$ & $2 / 3$ & $0.9560^{*}$ \\
\hline Period to shunt & 41 (17) & $49(23)$ & $55(24)$ & 0.2971 * & 40 (17) & $52(25)$ & 40 (17) & $0.4032^{*}$ \\
\hline HDS-R & $5.0(4.8)$ & $0.0(0.0)$ & $2.8(5.2)$ & $0.2374^{*}$ & $5.0(4.8)$ & $0.0(0.0)$ & $2.8(5.2)$ & $0.6813^{*}$ \\
\hline m-Rankin & $4.1(1.0)$ & $4.7(0.6)$ & $4.8(0.4)$ & 0.2191 * & $4.1(1.0)$ & $4.7(0.6)$ & $4.8(0.4)$ & $0.4134^{*}$ \\
\hline Gait score & $1.9(1.4)$ & $1.0(0.0)$ & $1.0(0.0)$ & $0.5110^{*}$ & $1.9(1.4)$ & $1.0(0.0)$ & $1.0(0.0)$ & $0.6925^{*}$ \\
\hline Incontinence & $10 / 13$ & $3 / 3$ & $5 / 5$ & $0.6855^{\star}$ & $10 / 13$ & $3 / 3$ & $5 / 5$ & $0.8353^{*}$ \\
\hline $\mathrm{NAA} / \mathrm{Cr}$ & $1.69(0.20)$ & $1.34(0.08)$ & $1.15(0.12)$ & $0.0009^{*}$ & $1.68(0.24)$ & $1.41(0.21)$ & $1.30(0.28)$ & $0.0335^{*}$ \\
\hline NAA/Cho & $1.58(0.34)$ & $1.28(0.31)$ & $1.09(0.21)$ & $0.0092^{*}$ & $1.68(0.34)$ & $1.21(0.12)$ & $1.17(0.17)$ & $0.0035^{*}$ \\
\hline Cho/Cr & $1.10(0.17)$ & $1.08(0.20)$ & $1.07(0.14)$ & $0.8770^{*}$ & $1.02(0.18)$ & $1.16(0.16)$ & $1.11(0.11)$ & 0.3031 * \\
\hline $\mathrm{mlns} / \mathrm{Cr}$ & $0.24(0.08)$ & $0.29(0.14)$ & $0.37(0.10)$ & $0.0542^{*}$ & $0.26(0.08)$ & $0.25(0.12)$ & $0.35(0.12)$ & $0.1798 *$ \\
\hline
\end{tabular}

${ }^{*}$ Calculated after conversion to a binary value. Bold faced values are significant $(p<0.05)$.

Cho, choline compounds; Cr, creatine; HDS-R, Hasegawa's dementia scale; mlns, myoinositol; m-Rankin, modified Rankin scale; NAA, N-acetylaspartate. 
Rankin scores were three, four, and four, respectively. Urinary incontinence persisted postoperatively in seven patients. In two patients (cases 9 and 13), only minor improvement was seen, resulting in no score changes in any of these four assessments, while improvement was seen for at least one of these evaluation categories in the remaining 19 patients. Seven patients still had dementia, with an HDS-R score less than 20, while six could not walk independently. Overall clinical outcome was excellent in 13 patients, fair in three, and poor in five. Significant differences in NAA/Cr and NAA/Cho were evident between the excellent and poor outcome groups $(\mathrm{p}=0.0014$ and $\mathrm{p}=0.0036$, respectively), as were significant differences in $\mathrm{NAA} / \mathrm{Cr}$ between the excellent and fair outcome groups $(p=0.0186$, MannWhitney U test, fig 2). No significant differences were noted between the three outcome groups in preoperative variables including age, sex, Cho/Cr ratio, mIns/Cr ratio, and period from admission to shunt (table 2). No significant changes were noted in NAA/Cr ratio, NAA/Cho ratio, Cho/Cr ratio, or mIns/Cr ratio after ventriculo-peritoneal shunting (Student's paired $t$ test, fig 3).

Neurological status 12 months after shunting was evaluated in all patients except for one who died of pneumonia and another lost to follow up. Outcome in 10 patients was excellent, in five fair, and in four poor. Differences in NAA/Cr were significant between the excellent and poor outcome groups $(p=0.0237)$, as were differences in NAA/Cho between these groups (excellent-poor; $\mathrm{p}=0.0072$, excellent-fair; $p=0.0071$, Mann-Whitney $U$ test, fig 2). In three patients clinical outcome had deteriorated at 12 months from that at one month, from excellent to fair in two patients (cases 15 and 17), and from excellent to poor in one patient (case 3 ). On the other hand, two patients showed improvement in clinical outcome, one from fair to excellent (case 8) and the other from poor to fair (case 18). A subdural effusion and progressive subcortical atrophy developed in one patient (case 3, fig 3) who was diagnosed with vascular dementia. One patient (case 17) was suspected of having shunt malfunction because of neurological deterioration and underwent shunt revision, but neurological symptoms did not improve. Lacunar infarction and mild subcortical atrophy became evident by one year of follow up in one patient (case 15).

The relations between NAA/Cr or NAA/Cho and neurological scores including HDS-R, gait, urinary incontinence, and the m-Rankin scale were analysed by Spearman's rank correlation test. A significant correlation was seen between the NAA/Cr or NAA/Cho ratio and neurological status at one and 12 months after ventriculo-peritoneal shunting.

\section{Determination of predictive variables before shunting} Relations between factors observed preoperatively were analysed by Spearman's rank correlation coefficient. The modified Rankin score was related positively to age; variables related negatively included NAA/Cho, HDS-R, gait score, and incontinence. NAA/Cr and NAA/Cho ratios related negatively to the modified Rankin score. Correlations between HDS-R, gait score, urinary incontinence, and modified Rankin score were also significant.

\section{Multiple regression analysis of preoperative variables for predicting outcome at one month}

We analysed correlations of preoperative variables including age, sex, interval from admission to shunting, NAA/Cr, NAA/ Cho, Cho/Cr, mIns/Cr, HDS-R, gait score, incontinence, and modified Rankin score with outcome. Variables most predictive of outcome were $\mathrm{NAA} / \mathrm{Cr}$ ratio $(\mathrm{p}=0.0001)$, modified Rankin score $(p=0.0157)$, and gait score $(p=0.0143)$. Considering all three together, predictive value, sensitivity, and specificity for an excellent outcome after shunting were $95.2 \%, 100 \%$, and $87.5 \%$, respectively. The results suggest that higher values for $\mathrm{NAA} / \mathrm{Cr}$ ratio, gait score, and modified Rankin score predict better outcomes one month after shunting. The multiple correlation coefficient after adjustment of degrees of freedom was 0.7629. AID analysis suggested that the NAA/Cr ratio correlated highly with patient outcome at one month after ventriculoperitoneal shunting. In predicting the outcome of a patient, an $\mathrm{NAA} / \mathrm{Cr}$ ratio of at least 1.4 would suggest an excellent outcome, with predictive value, sensitivity, and specificity of $90.5 \%, 92.3 \%$, and $87.5 \%$, respectively.

\section{Multiple regression analysis of preoperative variables in predicting outcome at one year}

According to the AIC method, the best preoperative predictor was the NAA/Cho ratio. The multiple correlation coefficient with adjusted degree of freedom was $0.3739(\mathrm{p}<0.0032)$. Predictive value, sensitivity, and specificity calculated from the receiver operating characteristic (ROC) curve were 89.5\%, $90.0 \%$, and $88.9 \%$, respectively. AID analysis suggested that the NAA/Cho ratio correlated closely with the outcome of patients one year after ventriculo-peritoneal shunting. When predicting that the outcome of a patient with an NAA/Cho ratio of $\geqslant 1.6$ would be excellent, the predictive value, sensitivity, and specificity of NAA/Cho were $84.2 \%, 70.0 \%$, and $100 \%$.

\section{DISCUSSION}

Our study showed that measuring NAA/Cr or NAA/Cho ratio in the cerebral hemispheric white matter of NPH patients could predict the clinical effectiveness of CSF shunting. The concentration of NAA is a well known neuronal marker, thought to indicate viability of these cells. In a recent study, loss of NAA correlated with axonal degeneration and loss, validating MR spectroscopy as a way of evaluating axonal loss in white matter. ${ }^{10}$ In the present study, patients with an excellent outcome showed a tendency towards higher preoperative $\mathrm{NAA} / \mathrm{Cr}$ and NAA/Cho ratios in white matter, supporting the view that reduction of NAA in white matter reflects irreversible axonal injury-shown here by poor responsiveness of symptoms to CSF shunting. Reversible NAA depletion can be seen in some cases such as mitochondrial disease ${ }^{11}$ and other brain disorders, ${ }^{12}{ }^{13}$ and NAA depletion does not necessarily indicate neuronal loss. As NAA is synthesised in mitochondria and turns over within days, inhibition of the mitochondrial oxidative phosphorylation can cause NAA depletion. ${ }^{14}$ Such a reversible change in NAA, however, could be negligible in NPH patients, because no changes in NAA/Cr and NAA/Cho ratios were observed after ventriculo-peritoneal shunting in this study. We have no satisfactory explanation for these results. Our speculation is that clinical improvement after ventriculo-peritoneal shunting in NPH patients may not be the result of the restoration of the energy charge in neurones that may occur in acute hydrocephalus. Subependymal extracellular fluid accumulation, which appears to be responsible for the dysfunction of the axons and myelin or the disturbance of the glia-neuronal interaction, would cause a relative reduction in cellular density in the white matter. Fluid accumulation in the extracellular space would not change the NAA/Cr ratio until irreversible neuronal loss has occurred.

Quantitation of chemical concentrations is essential to clarify whether changes in NAA/Cr and NAA/Cho ratios result from actual changes in NAA. This may be possible by using the water signal as an internal standard, but would require measurement of water content in the selected area. Measurement of tissue water content imposes technical complexities for which we have no clinically useful MR 
technique. While water content could be assumed to be a uniform $75 \%,{ }^{15}$ it almost certainly changes under pathological conditions. Extracellular fluid is assumed to increase in an area of $\mathrm{PVH}^{16}{ }^{17}$ because CSF diffuses into periventricular white matter with compensatory absorption into capillaries. According to Capizzano et al, ${ }^{5}$ who measured brain chemical components directly by MR spectroscopy, creatine concentration in white matter did not differ between healthy volunteers and patients with dementia, while the concentration of NAA differed significantly. Thus total creatine concentration can be used for semiquantification by assuming a constant creatine concentration in the brain. Unlike water, the creatine signal can be used as an internal standard with no additional time requirement for quantitative measurement.

To date, a trial of external lumbar drainage or infusion test has seemed to be the best way of predicting the efficacy of CSF shunting. ${ }^{18-20}$ Haan and Thomeer ${ }^{21}$ reported that all 12 of their patients who showed a good response to lumbar drainage benefited from CSF shunting, while none of the five patients without amelioration from lumbar drainage improved after shunting. Although lumbar drainage carries a risk of complications such as meningitis, root irritation, intracranial hypotension, and tension pneumocephalus, we do not think that MR spectroscopy can replace lumbar drainage in evaluating clinical indications for CSF shunting in a patient. However, lumbar drainage findings alone cannot predict the outcome in patients who undergo CSF shunting. Lumbar drainage should be discontinued as soon as improvement is observed to reduce the risk of complications, so clinical observations during this procedure are necessarily short term. As for shunting, a review by Hebb and Cusimano $^{22}$ indicated a complication rate of $38 \%$, and a rate of permanent neurological deficit or death of $6 \%$. Thus shunting decisions require a risk-benefit assessment including the most informative prognostic information available. As the present study demonstrated the value of MR spectroscopy in predicting outcome, we consider it an important investigation before CSF shunting.

\section{Study limitations}

There are several limitations to our study. The sample size of 21 patients is small from a statistical point of view. Mechanisms of pathogenesis of NPH may not be limited to axonal dysfunction in white matter. Additional locations such as the hippocampus or basal ganglia should be examined. Moreover, the white matter area selected for the present study might not be representative of all white matter affected by hydrocephalus. For instance, more anterior voxels may have a better correlation with measures of gait. While multivoxel analysis could address this problem by evaluating local differences in concentrations of compounds, data obtained from a single voxel are more reliable, as more acquisition is possible than with multivoxel analysis.

We used a short echo time in an attempt to detect changes in glutamine/glutamate. However, we found difficulties in fitting curves to these partially overlapping peaks. A longer repetition time than six seconds might be better to avoid ambiguities from relaxation effects in multiple compounds. However, a long repetition time unduly prolongs the acquisition time, which is then disturbed by movement artefacts.

We agree that a quantitative analysis would have been much stronger than simply determining the ratios of peak areas, as concentrations of creatine in the white matter may be different in each patient. For precise evaluation of concentration of compounds of interest, an external standard ${ }^{23}$ or development of a reliable technique for measurement of water content are needed.

\section{Conclusions}

MRS is a useful assessment tool for prediction of outcomes after ventriculo-peritoneal shunting, and this may be particularly useful when the decision to shunt is complicated by either primary or antecedent medical conditions.

\section{ACKNOWLEDGEMENTS}

We thank Mr Tsuyoshi Matsuda at GE Yokogawa Medical for technical support, and Dr Akio Yoden at the Biostatistics Department of Shionogi and Co Ltd for statistical analyses.

\section{Authors' affiliations}

A Shiino, M Matsuda, Department of Neurosurgery, Shiga University of Medical Science, Shiga, Japan

Y Nishida, Department of Ophthalmology, Shiga University of Medical Science

H Yasuda, Department of Neurology, Shiga University of Medical Science

M Suzuki, Department of Otolaryngology, Shiga University of Medical Science

T Inubushi, Department of Molecular Neuroscience Research Centre, Shiga University of Medical Science

Competing interests: none declared

\section{REFERENCES}

1 Adams RD, Fisher CM, Hakim S, et al. Symptomatic occult hydrocephalus with "normal" cerebrospinal fluid pressure. A treatable syndrome. N Engl J Med 1965;273:117-26.

2 Vanneste JAL. Three decades of normal pressure hydrocephalus: are we wiser now? J Neurol Neurosurg Psychiatry 1994;57:1021-5.

3 Hirai $\mathrm{O}$, Kikuchi $\mathrm{H}$, Ishikawa M. A nationwide survey on normal-pressure hydrocephalus in Japan Annual report of the research committee of "Intractable Hydrocephalus". The Ministry of Health and Welfare of Japan, 1991:137-44.

4 Simmons ML, Frondoza CG, Coyle JT. Immunocytochemical localization of $\mathrm{N}$-acetyl-aspartate with monoclonal antibodies. Neuroscience 1991;45:37-45.

5 Capizzano AA, Schuff N, Amend DL, et al. Subcortical ischemic vascular dementia: assessment with quantitative MR imaging and $1 \mathrm{H} M R$ spectroscopy. Am J Neuroradiol 2000;21:621-30.

6 Brooks WM, Wesley MH, Kodituwakku PW, et al. 1H-MRS differentiates white matter hyperintensities in subcortical arteriosclerotic encephalopathy from those in normal elderly. Stroke 1997;28:1940-43.

7 Shiino A, Matsuda M, Morikawa S, et al. Proton magnetic resonance spectroscopy with dementia. Surg Neurol 1993;39:143-7.

8 Hosokawa T, Yamada Y, Isagoda A, et al. Psychometric equivalence of the Hasegawa dementia scale-revised with the mini-mental state examination in stroke patients. Percept Mot Skills 1994;79:664-6.

9 van Swieten JC, Koudstaal PJ, Visser MC, et al. Interobserver agreement for the assessment of handicap in stroke patients. Stroke 1988; 19:604-7.

10 Bjartmar C, Battistuta J, Terada N, et al. N-acetylaspartate is an axon-specific marker of mature white matter in vivo: a biochemical and immunohistochemical study on the rat optic nerve. Ann Neurol 2002; $51: 51-8$

11 Ellis CM, Lemmens G, Williams SC, et al. Changes in putamen Nacetylaspartate and choline ratios in untreated and levodopa-treated Parkinson's disease: a proton magnetic resonance spectroscopy study. Neurology 1997;49:438-44

12 De Stefano N, Matthews PM, Arnold DL. Reversible decreases in $\mathrm{N}$-acetylaspartate after acute brain injury. Magn Reson Med 1995:34:721-7.

13 De Stefano N, Matthews PM, Antel JP, et al. Chemical pathology of acute demyelinating lesions and its correlation with disability. Ann Neurol 1995;38:901-9.

14 Dautry C, Vaufrey F, Brouillet E, et al. Early N-acetylaspartate depletion is a marker of neuronal dysfunction in rats and primates chronically treated with the mitochondrial toxin 3-nitropropionic acid. J Cereb Blood Flow Metab 2000;20:789-99

15 Christiansen $\mathbf{P}$, Henriksen $O$, Stubgaard $M$, et al. In vivo quantification of brain metabolites by $1 \mathrm{H}-\mathrm{MRS}$ using water as an internal standard. Magn Reson Imaging 1993;11:107-18.

16 Ogata J, Hochwald GM, Cravioto H, et al. Light and electron microscopic studies of experimental hydrocephalus. Ependymal and subependymal areas Acta Neuropathol (Berl) 1972;21:213-23.

17 Rubin RC, Hochwald GM, Tiell M, et al. Hydrocephalus: I. Histological and ultrastructural changes in the pre-shunted cortical mantle. Surg Neurol 1976;5:109-14.

18 Kahlon B, Sundbarg G, Rehncrona S. Comparison between the lumbar infusion and CSF tap tests to predict outcome after shunt surgery in suspected normal pressure hydrocephalus. J Neurol Neurosurg Psychiatry 2002;73:721-6.

19 Meier U, Miethke C. Predictors of outcome in patients with normal-pressure hydrocephalus. J Clin Neurosci 2003;10:453-9. 
20 Tans JT, Boon AJ. Dutch NPH Study Group: How to select patients with normal pressure hydrocephalus for shunting. Acta Neurochir Suppl 2002;81:3-5.

21 Haan J, Thomeer RT. Predictive value of temporary external lumbar drainage in normal pressure hydrocephalus. Neurosurgery 1988;22:388-91.
22 Hebb AO, Cusimano MD. Idiopathic normal pressure hydrocephalus: a systematic review of diagnosis and outcome. Neurosurgery 2001;49:1166-84.

23 Duc CO, Weber OM, Trabesinger AH, et al. Quantitative 1H MRS of the human brain in vivo based on the stimulation phantom calibration strategy. Magn Reson Med 1998;39:491-6.

\section{HISTORICAL NOTE}

\section{Positive and negative cerebral symptoms: the roles of Russell Reynolds and Hughlings Jackson}

$\mathrm{S}$ ir John Russell Reynolds (1828-1896) is often remembered for his description of eclamptic convulsions in children, ${ }^{1}$ which at that time referred to various fits including febrile convulsions. ${ }^{2}$ Reynolds also suggested electrotherapy in nervous diseases. ${ }^{3}$ Interestingly, he is widely quoted for his commendation of the "great value of Cannabis indica $^{\prime 4}$ in migraine, epileptic conditions, depression, and asthma.

Perhaps of greater import his 1861 paper $^{2}$ espoused ${ }^{5}$ the concept of positive and negative neurological symptoms as being the excess or negation of vital properties. Positive symptoms were abnormal "superimposed" behaviours that included not only clonic jerking and abnormal movements but also hallucinations and paranoid delusions. Negative symptoms included loss of sensation, paralysis, and coma. Unfortunately he failed to write further on this theme. Like Jackson, Reynolds also noted that the lesion did not directly cause the symptoms observed. ${ }^{1}$

The origins of positive and negative symptoms are inextricably intertwined with Herbert Spencer's dissolution and evolution of the nervous system. ${ }^{67}$ Hughlings Jackson extended Spencer's idea to positive and negative symptomatology. Jackson believed that negative symptoms related to dissolution of neural function while positive symptoms resulted from excitation or the release of lower levels from higher inhibitory control:

"...there are degrees of loss of function of the least organized nervous arrangements with conservation of function of the more organized. There is in each reduction to a more automatic condition; in each there is dissolution, using this term as Spencer does, as the opposite of evolution."

In the same paper Jackson goes onto apply this in the postepileptic state:

"Physically, - The negative element in the symptomatology is what the epileptic discharge produces; it is the dissolution... Pathologically it is so much exhaustion (effected by the prior epileptic discharge)...Physiologically, it is so much loss of function of so many nervous arrangements of the least organised, the continually organising centres...Anatomically, the negative elements are losses of adjustment of the organism, as a whole, to the environment in the order, according to the "depth" of the dissolution, from the most special and complex of them towards the most general and simple. Correspondingly, the positive elements are anatomically considered retentions, and often over-developments, of more general and simple adjustments of the organism as a whole to the environment..."

"...there is a negative state with each positive state; in each degree the patient's condition is thus duplex."

Jackson's writings9 apply this fundamental principle to aphasia, hemiplegia, and clonic and other movements; it also became applied in psychiatry, ${ }^{10}$ to the symptomatology of schizophrenia. The hierarchy of cerebral function comprised "lowest, middle, and highest - to indicate different evolutionary levels". 9 This effect manifested negative or positive symptoms. The concept became firmly established.

John Russell Reynolds was the son of a nonconformist minister who personally educated him. His grandfather was Henry Revell Reynolds, FRCP, a physician at the Middlesex and St Thomas's Hospitals. He trained at University College London, graduating with a gold medal in physiology, comparative anatomy, and medicine in 1851. Impecunious, he practised in Leeds where he had relatives, but was persuade by Marshall Hall, his former teacher, to return to London, where at modest cost Hall accommodated him in his home in Grosvenor Street. He was appointed assistant physician at the Hospital for Sick Children in 1855 and to the Westminster and then University College Hospitals where he became Holme Professor of Clinical Medicine in 1862, and in 1867 succeeded Jenner in the Chair of Medicine. From 1868 he was Dean. He edited A system of medicine (London: Macmillan), published in five volumes from 1866 to 1879 , a major text. Of his many distinguished students at University College Hospital were Bastian and Gowers.

Reynolds achieved high professional recognition. He gave both the Lumleian and Harveian lectures at the Royal College of Physicians of London, then became Censor and finally President from $1893-1896 .{ }^{11} \mathrm{He}$ was favoured as physician to the royal household in 1879 and was created baronet in 1895 . Concerned with medical politics, he was president of the BMA at the time of his death.

Generally regarded as a worthy, caring physician he was a popular and fluent lecturer, although shy and serious in manner. But, he showed a quiet sense of humour and directness ${ }^{11}$ when circumstances were apt. He was well versed in literature, art, and music. Twice married, he had no children. He died at his home in London.

J M S Pearce 304 Beverley Road, Anlaby, East Yorkshire HU10 7BG, UK; jmspearce@freenet.co.uk doi: 10.1136/jnnp.2004.038422

\section{References}

1 Reynolds JR. On the pathology of convulsions, with special reference to those children. Liverpool Med Chir J 1858;2:1-14.

2 Reynolds JR. Epilepsy: its symptoms. In: Treatment and relation to other chronic convulsive diseases. London: John Churchill, 1861:8-10.

3 Reynolds J. In: Russell lectures on the clinical uses of electricity delivered in University College Hospital. 2nd edn. London: John A Churchill, 1873.

4 Reynolds JR. Therapeutic uses and toxic effects of Cannabis indica. The Lancet 1890;1:639.

5 Devinsky O. In: Behavioural Maxims. London: Arnold, 1992:31.

6 Spencer H. Principles of psychology. London: Longman, Brown, Green, 1855.

7 Spencer H. First principles. London: Williams \& Norgate, 1911.

8 Jackson JH. Remarks on dissolution of the nervous system as exemplified by certain post-epileptic conditions. Medical Press and Circular 1881;329.

9 Jackson JH. In: Taylor J, ed. Selected writings of JH Jackson. London: Staples Press, 1958;2:3-92.

10 Andreasen NC, Olsen S. Negative v positive schizophrenia. Definition and validation. Arch Gen Psychiatry 1982;39:789-94.

11 Brown GH. Munk's Roll. Lives of the Fellows of the Royal College of Physicians of London (1826-1925). London: The Royal College of Physicians, 1955;IV:116-7. 